\title{
Live Performance and Processing Yields of Broilers Fed Diets With Tiamulin and Salinomycin Combinations
}

\begin{tabular}{l} 
- Author(s) \\
\hline Vieira $\mathrm{SL}^{1}$ \\
Favero $\mathrm{A}^{2}$ \\
Berres $\mathrm{J}^{2}$ \\
Freitas $\mathrm{DM}^{2}$ \\
Martinez JEP2 \\
Mayorga ME $\mathrm{ME}^{2}$ \\
Coneglian JLB2 \\
1 Associate Professor, Departamento de \\
Zootecnia, Universidade Federal do Rio \\
Grande do Sul - UFRGS. Porto Alegre, RS. \\
$2 \quad$ Aviário de Ensino e Pesquisa da UFRGS. \\
Porto Alegre, RS.
\end{tabular}

Mail Address

Sergio Luiz Vieira

Av. Bento Gonçalves, 7712

91.540-000. Porto Alegre, RS, Brazil

E-mail: slvieira@ufrgs.br

\section{Keywords}

Antibiotic, broiler, ionophores, salinomycin, tiamulin.

\section{ABSTRACT}

A study was conducted with the objective of evaluating the combined application of tiamulin (TIA) and salinomycin (SAL) in broiler diets fed from 1 to $42 \mathrm{~d}$ of age. One thousand and two hundred Cobb $\times$ Cobb 500 male broilers were housed in 48 floor pens and fed corn-soybean meal diets containing $66 \mathrm{ppm}$ of SAL combined or not with TIA at 30 or 20 and 20 or 15 ppm, respectively, in the starter (1-21 d) and grower feeds (22-42 d); however, TIA was withdrawn from the feeds 7 days before slaughter. The experimental design was completely randomized with 3 treatments and 16 replicates of 25 birds each. Broilers were weekly evaluated for live performance whereas carcass yield, abdominal fat and commercial cuts were assessed at $42 \mathrm{~d}$ using 6 birds randomly taken from each pen. Results obtained at the end of the study demonstrated that body weight gain was not affected $(P>0.05)$ by the treatments, whereas feed intake was reduced $(P<0.05)$ and feed conversion was improved $(P<0.05)$ for birds on diets containing TIA at 30/20 and 20/15 ppm, respectively. Carcass yield, abdominal fat, and commercial parts were not affected $(P>0.05)$ by the treatments. Live performance and post-slaughter yields data obtained in this study did not indicate that combinations of TIA with SAL could be detrimental. In fact, an improvement in feed conversion was observed at the lowest dose of TIA.

\section{INTRODUCTION}

lonophores have been added to broiler feeds with the objective of preventing coccidiosis for a long time. These compounds are divided into two general groups based on the mode of ion transfer across the cell membrane; channel formers or ion carriers (Kart \& Bilgili, 2008). Commercially grown animals generally use ion-carrier ionophores, which move ions across the membrane releasing them afterwards inside de cell. The protective effect of these drugs against coccidia is associated with their ability to change its ionic balance (Augustine et al., 1992). lonophores are generally safe and effective if used at recommended levels; however, ionophore toxicity might occur due to accidental overdoses, misuse, feed mixing errors as well as when combined factors lead to liver incapacity to fully metabolize them (Chapman, 2001; Nebbia et al. 1999).

Tiamulin (TIA) is a semi-synthetic antibiotic derived from pleuromutilin, which is recommended for the treatment of mycoplasmosis of poultry (Chapman \& Johnson, 2002). It has been used for animals for a long time, but its use in broilers has been frequently avoided due to reported incompatibilities with ionophores (Witkamp et al. 1995; Schuhmacher et al. 2006). Ataxia, leg weakness, and myopathy have been found in chickens and turkeys following the simultaneous administration of 


\section{Vieira SL, Favero A, Berres J,Freitas DM, Martinez JEP, Mayorga ME, Coneglian JLB}

Live Performance and Processing Yields of Broilers Fed Diets With Tiamulin and Salinomycin Combinations monensin and TIA (Horrox, 1980; Uchimura et al. 1978; Umemura et al. 1984). Inhibition of P450 3A enzyme isoform by TIA, which is responsible for the oxidation metabolism of monensin, was demonstrated, leading to accumulation of monensin in animal tissues (Chapman, 2001; Nebbia et al. 1999). It has been observed that toxic symptoms due to TIA and monensin combinations are identical to those produced by single overdoses of monensin (Hanrahan, 1981; Van Vleet et al. 1987).

Apparently, other ionophores may cause negative responses when used in combination with TIA for broilers, but the resulting effects depend on the type of ionophore and also on TIA levels (Meingassner et al., 1979). This has been the case of salinomycin and narasin; however, lasalocide has shown no negative effects when combined with TIA and fed to turkeys (Lodge et al., 1988). Semduramycin also seems not to interact with TIA probably due to a detoxification mechanism different from that of monensin (Schuhmacher et al., 2006).

Recently, TIA at 20 ppm has been reported to be safe when used along with SAL (Islam et al., 2008a), the interest in field applications of TIA in broilers. The objective of this study was to evaluate the effects of the combined supplementation of SAL with TIA on broiler live performance and carcass and commercial cuts yields. (Islam et al., 2008a) which has renewed the interest for field applications of TIA in broilers.

\section{MATERIAL AND METHODS}

One thousand and two hundred one-day-old Cobb X Cobb 500 (Cobb-Vantress Brasil Ltda) male broilers vaccinated for Marek's disease, were housed in 1,65 $x$ 1,70 floor-pen boxes, 25 birds in each. Chicks originated from broiler breeders previously tested and confirmed as free of Mycoplasmosis. Although placement was done only three days after removal of the previous flock, management was performed to maintain temperature within the comfort range. Live performance was weekly determined by pen group evaluations of body weight, feed intake, and feed conversion. Mortality was daily recorded, and the weight of dead birds was used to correct the feed conversion and evaluated via post mortem examination for the cause of death. Females eventually found were removed at $21 \mathrm{~d}$ of age. Broiler carcass evaluation was performed at 42 days of age on 6 birds randomly taken from each pen. Birds were individually weighed, and slaughtered using electrical stunning at $45 \mathrm{~V}$. Eviscerated carcasses without feet and heads were chilled in slush ice for $2 \mathrm{~h}$, allowed to drip for $2 \mathrm{~min}$, and were then weighed. Carcasses were cut into commercial parts by trained processing plant personnel and the following cuts were produced: breast fillets, tenders, thighs, drumsticks, wings, and abdominal fat. All cuts were individually weighed and their yields were expressed as percentage of the carcass.

Corn-soybean meal mash feeds were formulated using a two-phase feeding program: starter from 1 to $21 \mathrm{~d}$ and grower from 22 to $42 \mathrm{~d}$ (Table 1). Energy and nutrients were similar to those used in Brazilian integrations. Group 1 comprised the negative control birds, which were fed a diet containing 66 ppm SAL (Coxistac ${ }^{\circledR}$ $12 \%$, Phibro Animal Health) only, whereas Groups 2 and 3 were given SAL at 66 ppm and also TIA (Denegard ${ }^{\circledR}$ $10 \%$, Novartis Animal Health) at 30 and 20 ppm or 20 and 15 ppm from 1 to $21 \mathrm{~d}$ and $21-42 \mathrm{~d}$, respectively. All drugs were continuously administered via their respective feeds and diet. All feeds were assayed for TIA and all were found to contain the appropriate level of drug. Mean drug concentration of SEM-containing feeds was $66 \mathrm{ppm}$. No other antibiotic was used in the feeds and TIA was removed from the feeds 7 days before slaughter.

\begin{tabular}{|c|c|c|}
\hline Ingredients, \% & $1-21$ & $22-42$ \\
\hline Corn & 55.55 & 61.17 \\
\hline Soybean meal $45,6 \%$ CP & 37.65 & 31.00 \\
\hline Dicalcium phosphate & 1.83 & 1.57 \\
\hline Limestone & 0.59 & 0.48 \\
\hline L-Lysine $\mathrm{HCl}$ & 0.17 & 0.19 \\
\hline Salt & 0.31 & 0.34 \\
\hline Choline chloride & 0.09 & 0.06 \\
\hline DL - Methionine & 0.26 & 0.23 \\
\hline Sodium bicarbonate & 0.32 & 0.01 \\
\hline Soybean oil & 3.00 & 4.72 \\
\hline L-Threonine & 0.06 & 0.06 \\
\hline Vitamin and mineral premix ${ }^{1}$ & 0.17 & 0.17 \\
\hline \multicolumn{3}{|c|}{ Energy and Nutrients, \% or as indicated } \\
\hline $\mathrm{ME}, \mathrm{kcal} / \mathrm{kg}$ & 3,025 & 3,240 \\
\hline$C P$ & 22.00 & 19.42 \\
\hline $\mathrm{Ca}$ & 0.95 & 0.80 \\
\hline Av. $P$ & 0.46 & 0.40 \\
\hline $\mathrm{K}$ & 0.92 & 0.81 \\
\hline $\mathrm{Na}$ & 0.23 & 0.16 \\
\hline $\mathrm{Cl}$ & 0.28 & 0.30 \\
\hline Choline, mg/kg & 1,800 & 1,500 \\
\hline \multicolumn{3}{|l|}{ Digestible aminoacids, \% } \\
\hline Lysine & 1.20 & 1.06 \\
\hline Methionine + Cysteine & 0.85 & 0.76 \\
\hline Threonine & 0.78 & 0.69 \\
\hline Tryptophan & 0.24 & 0.20 \\
\hline Valine & 0.90 & 0.82 \\
\hline Isoleucine & 0.78 & 0.71 \\
\hline
\end{tabular}

1Composition per kg of diet: A - 5,000 IU; D3 - 1,000 IU; E - 20 IU; K3 - 0.9 mg; B1 - 0.6 mg; B2 - 3 mg; B6 - 1 mg; B12 - 6 mcg; Niacin - 15 $\mathrm{mg}$; Pantothenic acid - $7 \mathrm{mg}$; Biotin - $0.04 \mathrm{mg}$; Folic acid - $0.5 \mathrm{mg} ; \mathrm{Zn}$ - 51 mg; Mn - 67.5 mg; Cu - 8 mg; Fe - 64 mg; I - 0.72 mg; Se - 0.28 $\mathrm{mg}$ 
The study was conducted according to a completely randomized design with 3 treatments of 16 replicates each. Resulting data was submitted to ANOVA and Tukey's (SAS Institute, 2001) test was used to separate the means when treatment differences were significant $(P<0.05)$.

\section{RESULTS AND DISCUSSION}

Live performance data are presented on Table 2 . Analyzed feeds contained SAL and TIA levels that corresponded to expected inclusions. Broilers fed diets with SAL + TIA (30/20 ppm) showed lower feed intake and body weight gain $(P<0.05)$ from 14 to $21 \mathrm{~d}$ as compared to the diet without TIA. During the overall period, reduced feed intake was observed in birds fed TIA (30/20 ppm); however, no effect was observed on body weight $(P>0.05)$. Feed conversion significantly improved in birds fed TIA (20/15 ppm) during weeks corresponding to 14-21 and 35-42 d, as well as during the overall period. The use of TIA (30/20 ppm) promoted better results than the control treatment from 21 to $28 \mathrm{~d}(\mathrm{P}<0.05)$. Overall bird mortality was low (grand mean $=2.36 \%)$, and was not affected by the treatments $(P>0.05)$.

Carcass data resulting from processing (Table 3 ) did not show statistical significant differences among treatments $(P>0.05)$. The present study evaluated the animal responses that are usually measured in commercial environments. Therefore, discussions and conclusions from this study cannot provide further explanations regarding mode of action of SAL, TIA or their combination.

Results of the present investigation demonstrate that the continuous use of TIA (30 - 20ppm) in feeds containing SAL (66 ppm) were safe. No clinical signs of toxicity, such as high mortality, leg weakness, myophathy or any other muscle lesions were observed in live animals or carcasses. Reports that found incompatibilities between TIA and ionophores generally applied TIA at $150 \mathrm{ppm}$ and $250 \mathrm{ppm}$ in feed and water, respectively (Schuhmacher et al. 2006; Stipkovits et al. 1999) with the medicated feeds and water supplied for periods of 7 and $5 \mathrm{~d}$, respectively. In those cases, some birds showed mild signs of incompatibilities characterized by reduced feed intake and body weight, but no mortality.

Medication programs with high TIA doses often lead to anorexia and live performance losses during the period of concurrent administration of TIA and ionophores. However, when TIA treatment was withdrawn, there were significant compensatory improvements in feed efficiency and differences in body weight could not be detected during the subsequent periods (Schuhmacher et al. 2006; Islam et al. 2008b).

\begin{tabular}{|c|c|c|c|c|c|c|c|}
\hline \multicolumn{8}{|c|}{ Body Weight Gain, g } \\
\hline Treatments, ppm & $1-7$ & $7-14$ & $14-21$ & $21-28$ & $28-35$ & $35-42$ & $1-42$ \\
\hline T1 - Negative Control & 98 & 226 & $442 a$ & 553 & 652 & 666 & 2.637 \\
\hline T2 - Tiamulin (20/15) & 88 & 221 & $435 a b$ & 572 & 692 & 674 & 2.682 \\
\hline T3 - Tiamulin (30/20) & 90 & 215 & $422 \mathrm{~b}$ & 560 & 658 & 675 & 2.620 \\
\hline Mean & 92 & 221 & 432 & 562 & 677 & 672 & 2.647 \\
\hline$P$ values & 0.18 & 0.12 & 0.01 & 0.30 & 0.22 & 0.32 & 0.41 \\
\hline CV \% & 9.17 & 5.07 & 3.53 & 4.41 & 6.32 & 8.85 & 4.06 \\
\hline \multicolumn{8}{|c|}{ Feed Intake, g } \\
\hline Treatments, ppm & $1-7$ & $7-14$ & $14-21$ & $21-28$ & $28-35$ & $35-42$ & $1-42$ \\
\hline T1 - Negative Control & 114 & 313 & $559 a$ & 855 & 1.108 & 1.357 & $4.306 \mathrm{a}$ \\
\hline T2 - Tiamulin (20/15) & 103 & 302 & $532 a b$ & 838 & 1.099 & 1.316 & $4.190 \mathrm{ab}$ \\
\hline T3 - Tiamulin (30/20) & 106 & 303 & $523 b$ & 827 & 1.061 & 1.356 & $4.176 \mathrm{~b}$ \\
\hline Mean & 107 & 306 & 538 & 840 & 1.089 & 1.343 & 4.190 \\
\hline$P$ values & 0.37 & 0.35 & 0.03 & 0.10 & 0.25 & 0.67 & 0.03 \\
\hline CV \% & 10.04 & 4.89 & 4.47 & 3.45 & 4.75 & 7.40 & 2.85 \\
\hline \multicolumn{8}{|c|}{ Feed Conversion } \\
\hline Treatments, ppm & $1-7$ & $7-14$ & $14-21$ & $21-28$ & $28-35$ & $35-42$ & $1-42$ \\
\hline T1 - Negative Control & 1.166 & 1.384 & $1.265 \mathrm{~b}$ & $1.548 \mathrm{~b}$ & 1.699 & $2.037 \mathrm{~b}$ & $1.632 \mathrm{~b}$ \\
\hline T2 - Tiamulin (20/15) & 1.172 & 1.363 & $1.223 \mathrm{a}$ & $1.466 a b$ & 1.588 & $1.956 \mathrm{a}$ & $1.560 \mathrm{a}$ \\
\hline T3 - Tiamulin (30/20) & 1.178 & 1.415 & $1.239 a b$ & 1.458 a & 1.612 & $2.008 a b$ & $1.594 \mathrm{ab}$ \\
\hline Mean & 1.172 & 1.385 & 1.243 & 1.491 & 1.633 & 2.000 & 1.595 \\
\hline$P$ values & 0.99 & 0.28 & 0.01 & 0.01 & 0.17 & 0.01 & 0.01 \\
\hline CV \% & 5.66 & 3.88 & 2.11 & 2.97 & 5.73 & 7.31 & 2.95 \\
\hline
\end{tabular}

a,b Means within columns with no common superscript are significantly different $(P<0.05)$. Values within parentheses adjacent to tiamulin stand for the doses in the starter and grower feeds, ppm. 


\section{Vieira SL, Favero A, Berres J,Freitas DM, Martinez JEP, Mayorga ME, Coneglian JLB}

\begin{tabular}{|c|c|c|c|c|c|c|c|}
\hline Treatments, ppm & Carcass & Fat & Thighs & Drum & Breast & Tender & Wings \\
\hline T1 - Negative Control & 77.14 & 1.71 & 14.06 & 18.72 & 23.94 & 4.96 & 11.24 \\
\hline T2 - Tiamulin (20/15) & 77.83 & 1.43 & 13.71 & 18.70 & 24.98 & 4.89 & 11.30 \\
\hline T3 - Tiamulin (30/20) & 77.77 & 1.42 & 13.72 & 18.64 & 24.85 & 5.02 & 11.31 \\
\hline Mean & 77.58 & 1.52 & 13.83 & 18.69 & 24.59 & 4.96 & 11.28 \\
\hline$P$ values & 0.7241 & 0.0735 & 0.5659 & 0.6486 & 0.1443 & 0.1188 & 0.7916 \\
\hline$C V \%$ & 4.31 & 17.44 & 5.21 & 6.83 & 5.86 & 5.21 & 5.55 \\
\hline
\end{tabular}

$(\mathrm{P} \leq 0.05) .{ }^{*}$ Values within parentheses adjacent to tiamulin stand for the doses in the starter and grower feeds, ppm.

Pulse medication of broilers from 1 to 10 and 21 to $27 \mathrm{~d}$ with TIA at $0,20,30$, or $50 \mathrm{ppm}$ did not affect the live performance of broilers fed SAL at $60 \mathrm{ppm}$ (Islam et al., 2008b). Actually, some studies showed that TIA at 20 and 30 ppm improved body weight gain and feed conversion (Islam et al. 2008a; Islam et al. 2008b). Considering production cost, Islam et al. (2008a) found that $30 \mathrm{ppm}$ of TIA produced the best economic return per unit of body weight gain.

\section{CONCLUSIONS}

Tiamulin included in broiler diets and fed from 1 to 21 and 22 to 42 days at 20 and 15 ppm, respectively, led to improvements in feed conversion.

The administration of $30 / 20$ or $20 / 15$ ppm of TIA in diets from 1 to 21 and 22 to 42 days of age, which also contained 66 ppm SAL, did not impair broiler performance when evaluated using industry standard measurements of live performance and processing yields.

\section{REFERENCES AND NOTES}

Augustine PC, Walkins KL, and Danforth HD. Effects of monensin on ultrastructure and cellular invasion by turkey coccidian Eimeria adenoeides and Eimeria meleagrimitis. Poultry Science 1992; 71:970-978.

Chapman HD. Use of anticoccidial drugs in broiler chickens in the United States: Analysis for the years 1995 to 1999. Poultry Science, 2001; 80:572-580.

Chapman HD, Johnson ZB. Use of antibiotics and roxarsone in broiler chickens in the USA: Analysis for the years 1995 to 2000. Poultry Science, 2002; 81:356-364.

Hanrahan L, Corrier D, Nagi S. Monensin toxicosis in broiler chickens. Veterinary Pathology 1981; 18:665-671.

Horrox NE. Monensin-tiamulin interaction risk to poultry. Veterinary Record 1980; 106:278.

Islam KMS, Afrin S, Khan MJ, Das PM, Hassan MM, Valks M, Burch DGS, Pesti GM. Compatibility of a combination of tiamulin plus chlortetracycline with salinomycin in feed during a long-term coadministration in broilers. Poultry Science 2008a; 87:1565-1568.

Islam KMS, Afrin S, Das PM, Hassan MM, Valks M, Klein U, Burch DGS, Kemppainen BW. Compatibility of a combination of tiamulin and chlortetracycline with salinomycin in feed during a pulsed medication program co-administration in broilers. Poultry Science 2008b; 87:2528-2534.

Kart A, Bilgili A. Ionophore antibiocits: Toxicity, mode of action and neurotoxic aspect of carboxylic ionophores. Journal of Animal and Veterinary Advances 2008; 6:748-751.

Lodge NJ, Comben N, Roberts NL, Fairley C. Safety of lasalocid in turkeys and its compatibility with tiamulin. Veterinary Record 1988; 122:576-578.

Meingassner J, Schmook F, Czok R, Mieth H. Enhancement of the anticoccidial activity of polyether antibiotics in chickens by tiamulin. Poultry Science 1979; 58:308-313.

Nebbia C, Ceppa L, Dacasto M, Carletti M, Nachtmann C. Oxidative metabolism of monensin in rat liver microsomes and interactions with tiamulin and other chemotherapeutic agents: Evidence of the involvement of cytochrome $P-4503^{\text {a }}$ subfamily. Drug Metabolism and Disposition 1999; 27:1039-1044.

SAS Institute. SAS User's Guide. Version 8 ed. SAS Inst. Inc., Cary, NC 2001.

Schuhmacher A, Bafundo KW, Islam KMS, Aupperle H, Glaser R, Schoon HA, Gropp JM. Tiamulin and semduramicin: effects of simultaneous administration on performance and health of growing broiler chickens. Poultry Science 2006; 85:441-445.

Stipkovits L, Salyi G, Glavits R, Burch DGS. Testing the compatibility of a combination of tiamulin/chlortetracycline 1:3 premix (Tetramutin-Novartis) given in feed at different levels with salinomycin in chickens. Avian Pathology 1999; 28:579-586.

Uchimura M, Iwasaki H, Asaoka M, Tsuchiya H, Udatsu S, Hamaguchi S, Oshikawa N. Leg weakness of chickens due to combined administration of monensin and Terra-egg. Journal of the Japanese Society of Poultry Diseases 1978; 14:121-128.

Umemura T, Nakamura H, Goryo M, Itakura C. Histopathology of monensin-tiamulin myopathy in broiler chicks. Avian Pathology $1984 ; 13: 459-467$

Van Vleet J, Runnels L, Cook J, Scheidt A. Monensin toxicosis in swine: Potentiation by tiamulin administration and ameliorative 
Vieira SL, Favero A, Berres J,Freitas DM, Martinez JEP, Mayorga ME, Coneglian JLB
Live Performance and Processing Yields of Broilers Fed Diets With Tiamulin and Salinomycin Combinations

effect of treatment with selenium and/ or vitamin E. American Journal of Veterinary Research 1987; 48:1530-1534.

Witkamp R, Nijmeijer S, Monshouwer M, Van Miert A. The antibiotic tiamulin is a potential and inhibitor of cytochrome P-450/3A via the formation of a stable metabolic intermediate complex. Drug Metabolism and Disposition 1995; 23:542-547. 